\title{
Variability of choroidal and retinal thicknesses in healthy eyes using swept-source optical coherence tomography - implications for designing clinical trials
}

\author{
This article was published in the following Dove Press journal: \\ Clinical Ophthalmology \\ 12 October 2017 \\ Number of times this article has been viewed
}

\section{Albert Caramoy' \\ Ludwig $\mathrm{M} \mathrm{Heindl}^{2}$}

'Eye Center Wolfsburg-Fallersleben, Wolfsburg, ${ }^{2}$ Department of Ophthalmology, University of Cologne, Cologne, Germany
Correspondence: Albert Caramoy Eye Center Wolfsburg-Fallersleben, Am Spieker 10, Wolfsburg 38442, Germany

Email acaramoy@yahoo.co.uk
Aim: The aim was to study the variability of choroidal scleral interface (CSI) thickness in healthy subjects and its relevance for designing future studies.

Methods: A total of 123 volunteers were imaged using swept-source optical coherence tomography. Early treatment diabetic retinopathy grid was used.

Results: Mean central retinal thickness was $285.85 \pm 14.53 \mu \mathrm{m}$ and $287.18 \pm 12.93 \mu \mathrm{m}$, and mean central CSI thickness was $273.94 \pm 77.77 \mu \mathrm{m}$ and $271.19 \pm 78.85 \mu \mathrm{m}$ for the right and left eyes, respectively. Mean retinal and CSI thicknesses correlated negatively with age ( $p=0.023$, $r=-0.208$ and $p<0.0001, r=-0.426$, respectively) and axial length $(p=0.016, r=-0.220$ and $p<0.0001, r=-0.504$, respectively). To detect a CSI change of at least $112 \mu \mathrm{m}$, a sample size of 11 or 36 per group is needed for a single- or double-arm study, respectively ( $\alpha=0.05$, power $=0.90$, no loss to follow-up, assuming standard deviation in future studies as $100 \mu \mathrm{m}$ ).

Conclusion: Future clinical studies using CSI as end point are possible with regard to sample size needed.

Keywords: swept-source optical coherence tomography, choroidal thickness, retinal thickness, clinical trials

\section{Introduction}

The development of optical coherence tomography has revolutionized the ophthalmology. Using this technology, we are able to produce a high-detailed image of the retina. In recent years, the development of swept-source technology has enabled us to produce images in a much faster way. ${ }^{1}$ Also, the use of 1,050 nm wave length enables us to penetrate the retina much better, therefore allowing a deeper penetration into the choroid. ${ }^{2}$

Several authors have shown that choroidal thickness is associated with retinal diseases such as central serous chorioretinopathy and age-related macular degeneration. ${ }^{3-6}$ However, choroidal thickness is also influenced by other factors, such as axial length. ${ }^{7-9}$ Although visual acuity is a common parameter measured in clinical trials, there is a need to examine secondary end points as well. For example, in trials in which cataract is a common adverse event, objective measurements of retina and choroid are desirable.

Therefore, the exact measurements of choroidal thickness in healthy individuals are essential for future clinical research using this parameter. In the present study, 
we measure choroidal and retinal thicknesses in healthy participants. We examine its variability and relevance in designing clinical trials using this parameter.

\section{Patients and methods}

In this paper, we examined the retinal and choroidal thicknesses in 123 volunteers. Main inclusion criterion for the analysis was a best-corrected visual acuity (BCVA) better than 20/25 in both eyes. Exclusion criteria included signs of other ocular diseases compromising retinal thickness, such as early or late age-related macular degeneration, macular pucker, macular hole, vitreomacular traction, glaucoma, glaucoma suspect patients, and diabetic macular edema. All subjects underwent full ophthalmic examinations including BCVA measurement, slit lamp examination, binocular indirect ophthalmoscopy, fundus photography, and swept-source optical coherence tomography (SS-OCT). Subjects with insufficient quality of SS-OCT images were excluded from the analysis. All volunteers were examined in the University of Cologne. By doing this, there is a selection bias in the collective. This is however intended, because we would like to study the variability of healthy individuals, before moving to cross-sectional type study not excluding individuals with other ocular conditions. Informed consent was obtained from each subject. Some of the participants were under the legal age of consent, in this case written informed consents were provided by their parents or legal guardians. The study was approved by the ethic committee of the University of Cologne (number 15-177).

Axial length was measured using Zeiss IOLMaster 500 (Carl Zeiss Meditec AG, Jena, Germany). Retinal and choroidal thicknesses were measured using swept-source optical coherence tomography (DRI OCT-1; TopCon Corporation, Tokyo, Japan). Using this device, a retinal-choroidal map was produced. The Early Treatment Diabetic Retinopathy Study (ETDRS) grid was centered manually at the fovea. The following retinal layers were delineated automatically: RETINA, total retinal thickness from internal limiting membrane to Bruch's membrane; RNFL, retinal nerve fiber layer; GCLIPL, Ganglion cell layer and inner plexiform layer; RNFLGCLIPL, sum of retinal nerve fiber layer to inner plexiform layer; and CSI, choroid scleral interface. The thicknesses analyzed were the mean of all thickness within the ETDRS grid (Figure 1).

Statistical analyses were done using MedCalc version 16.8.4 (MedCalc Software bvba, Ostend, Belgium). Demographic characteristics of the population are described with summary statistics. Continuous data are presented with mean \pm standard deviation. Student's $t$-test for dependent variables is used, comparing the right eye and the left eye. Comparison
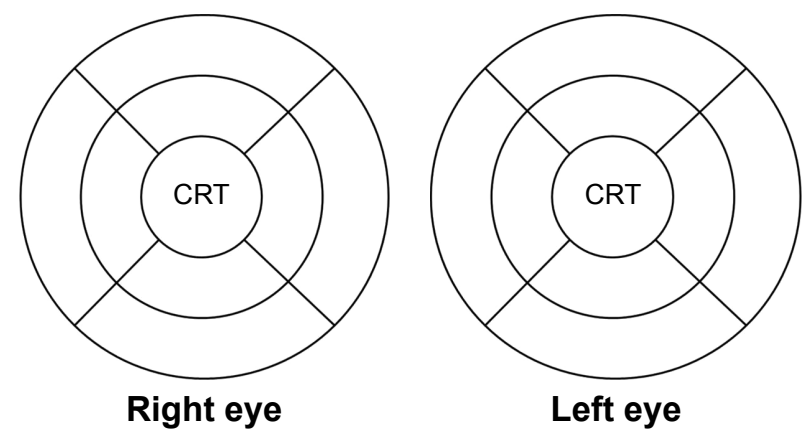

Figure I ETDRS grid used in this study.

Notes: The diameters of the central, middle, and outer rings are I, 3, and $6 \mathrm{~mm}$, respectively. CRT shows the central region within the $1 \mathrm{~mm}$ ring, centered at the fovea.

Abbreviation: ETDRS, Early Treatment Diabetic Retinopathy Study.

between eyes of different subjects was done using Student's $t$-test for independent variables. $p$-value $<0.05$ was deemed to be statistically significant. All correlations between two values are presented as Pearson product-moment correlation coefficient $(r)$. Sample size calculations were done using the G*Power 3 software (available at www.psycho. uni-duesseldorf.de/abteilungen/aap/gpower3/downloadand-register), which was described and developed by Faul et al. ${ }^{10,11}$ Sample size calculations for all hypothetical studies are done using the assumptions $\alpha=0.05$, power $=0.9$, and no loss to follow-up. ${ }^{12,13}$

\section{Results}

Among these volunteers, 45 were men (36.6\%) and 78 were women (63.4\%). A summary of demographic characteristics is shown in Table 1. Mean RETINA thickness was $285.85 \pm 14.53 \mu \mathrm{m}$ and $287.18 \pm 12.93 \mu \mathrm{m}$ for the right and left eyes, respectively. The mean RNFL was $29.43 \pm 3.16 \mu \mathrm{m}$ and $30.20 \pm 3.46 \mu \mathrm{m}$. For GCLIPL, the mean thickness was $75.95 \pm 5.94 \mu \mathrm{m}$ and $76.04 \pm 4.89 \mu \mathrm{m}$. The mean RNFLGCLIPL was $105.37 \pm 8.01 \mu \mathrm{m}$ and $106.22 \pm 6.92 \mu \mathrm{m}$. For CSI thickness, the mean thickness was $273.94 \pm 77.77 \mu \mathrm{m}$

Table I Summary of demographic characteristics

\begin{tabular}{|c|c|c|}
\hline Variables & \multicolumn{2}{|l|}{ Values } \\
\hline Age (years) & \multicolumn{2}{|c|}{$33.40 \pm 16.36$ (range: II-79) } \\
\hline \multicolumn{3}{|l|}{ Sex, n (\%) } \\
\hline Male & $45(36.6 \%)$ & \\
\hline \multirow[t]{2}{*}{ Female } & $78(63.4 \%)$ & \\
\hline & Right eye & Left eye \\
\hline Spherical refraction (D) & $\begin{array}{l}-0.86 \pm 1.86 \\
\text { (range: }-6.50 \text { to }+2.0 \text { ) }\end{array}$ & $\begin{array}{l}-0.84 \pm 1.95 \\
\text { (range: }-6.25 \text { to }+2.50)\end{array}$ \\
\hline Cup-to-disk ratio & $\begin{array}{l}0.25 \pm 0.10 \\
\text { (range: } 0-0.5 \text { ) }\end{array}$ & $\begin{array}{l}0.26 \pm 0.10 \\
\text { (range: } 0.1-0.5 \text { ) }\end{array}$ \\
\hline Axial length (mm) & $\begin{array}{l}24.01 \pm 1.26 \\
\text { (range: } 21.19-28.63 \text { ) }\end{array}$ & $\begin{array}{l}23.97 \pm 1.28 \\
\text { (range: } 21.11-28.44 \text { ) }\end{array}$ \\
\hline
\end{tabular}

Note: Values shown as $\mathrm{n}(\%)$ or mean \pm standard deviation (range). 
Table 2 Partial correlation between retinal and choroidal thicknesses, age, and axial length

\begin{tabular}{|c|c|c|c|c|}
\hline \multirow[t]{2}{*}{ Variables } & \multicolumn{2}{|l|}{ Age } & \multicolumn{2}{|c|}{ Axial length } \\
\hline & $r^{a}$ & $p$-value ${ }^{a}$ & $r^{b}$ & $p$-value ${ }^{b}$ \\
\hline Mean thickness (RETINA) & -0.208 & 0.023 & -0.220 & 0.016 \\
\hline Mean thickness in CRT (RETINA) & -0.012 & 0.894 & 0.230 & 0.012 \\
\hline Mean thickness (RNFL) & -0.085 & 0.356 & 0.367 & $<0.0001$ \\
\hline Mean thickness in CRT (RNFL) & -0.096 & 0.299 & 0.395 & $<0.0001$ \\
\hline Mean thickness (GCLIPL) & -0.209 & 0.022 & -0.257 & 0.005 \\
\hline Mean thickness in CRT (GCLIPL) & -0.040 & 0.665 & 0.260 & 0.004 \\
\hline Mean thickness (RNFLGCLIPL) & -0.180 & 0.050 & -0.021 & 0.820 \\
\hline $\begin{array}{l}\text { Mean thickness in CRT } \\
\text { (RNFLGCLIPL) }\end{array}$ & -0.058 & 0.533 & 0.316 & 0.0004 \\
\hline Mean thickness (CSI) & -0.426 & $<0.0001$ & -0.504 & $<0.0001$ \\
\hline Mean thickness in CRT (CSI) & -0.368 & $<0.0001$ & -0.513 & $<0.0001$ \\
\hline
\end{tabular}

Notes: For this purpose, measurements from the right eye and the left eye for each individual were averaged. aAdjusted for sex and axial length. ${ }^{b}$ Adjusted for sex and age.

Abbreviations: CRT, central retinal thickness; CSI, choroid scleral interface; RETINA, total retinal thickness from internal limiting membrane to Bruch's membrane; RNFL, retinal nerve fiber layer; GCLIPL, Ganglion cell layer and inner plexiform layer; RNFLGCLIPL, sum of retinal nerve fiber layer to inner plexiform layer.

(range: $81.77-480.56 \mu \mathrm{m}$ ) and $271.19 \pm 78.85 \mu \mathrm{m}$ (range: $76.56-471.22 \mu \mathrm{m})$ for the right and left eyes, respectively.

In patients with axial length $>23 \mathrm{~mm}$, mean CSI in the ETDRS region was $261.25 \pm 74.61 \mu \mathrm{m}$ and $259.43 \pm 75.63 \mu \mathrm{m}$ for the right and left eyes, respectively. Mean RETINA thickness was $285.37 \pm 15.01 \mu \mathrm{m}$ and $286.81 \pm 13.38 \mu \mathrm{m}$. In patients with axial length $\leq 23 \mathrm{~mm}$, mean CSI was $316.07 \pm 73.43$ and $307.34 \pm 75.51 \mu \mathrm{m}$. In these patients, mean RETINA was $286.25 \pm 13.93 \mu \mathrm{m}$ and $287.32 \pm 12.07 \mu \mathrm{m}$ for the right and left eyes, respectively.

The correlation between retinal choroidal thickness, age, and axial length is presented in Table 2. Overall CSI thickness within the ETDRS grid and within the central retinal thickness (CRT) region correlated significantly with age and axial length $(p<0.0001$, respectively). Male participants had no statistical difference in retinal thickness $(288.33 \pm 16.25 \mu \mathrm{m})$ compared to female participants $(284.43 \pm 13.34 \mu \mathrm{m}), t(121)=1.441, p=0.15$.

Overall, RETINA correlates with CSI ( $r=0.24, p=0.007$ for the right eye and $r=0.24, p=0.008$ for the left eye). The overall mean retinal thickness in ETDRS grid differed significantly between the right $(285.85 \pm 14.53 \mu \mathrm{m})$ and left eyes $(287.18 \pm 12.93 \mu \mathrm{m}), t(122)=3.124, p=0.002$. On comparing only the CRT regions, RETINA differed between both eyes of the same individual ( $p=0.005$ ). However, CSI in the CRT region did not differ between both eyes $(p=0.23)$. We found a considerable amount of concordance between CSI within ETDRS grid and within CRT region of the right and left eyes of the same individual (Figure 2A and B).

Mean absolute difference between CSI within ETDRS grid between both eyes of the same individual was 23.491 $\pm 20.877 \mu \mathrm{m}$ (range: $0.111-112 \mu \mathrm{m}$ ). The mean absolute difference of CSI in the CRT region between both eyes of the same individual was $33.366 \pm 29.459 \mu \mathrm{m}$ (range: $0-166 \mu \mathrm{m}$ ).

\section{Sample size calculation}

For designing future clinical trials using choroidal thickness measurements in SS-OCT as one possible primary end point, the sample size needed has to be defined in detail. In this study, we found choroidal thickness differences of up to $112 \mu \mathrm{m}$ in normal individuals between both eyes. Since CSI changes are a generalized change, we have chosen
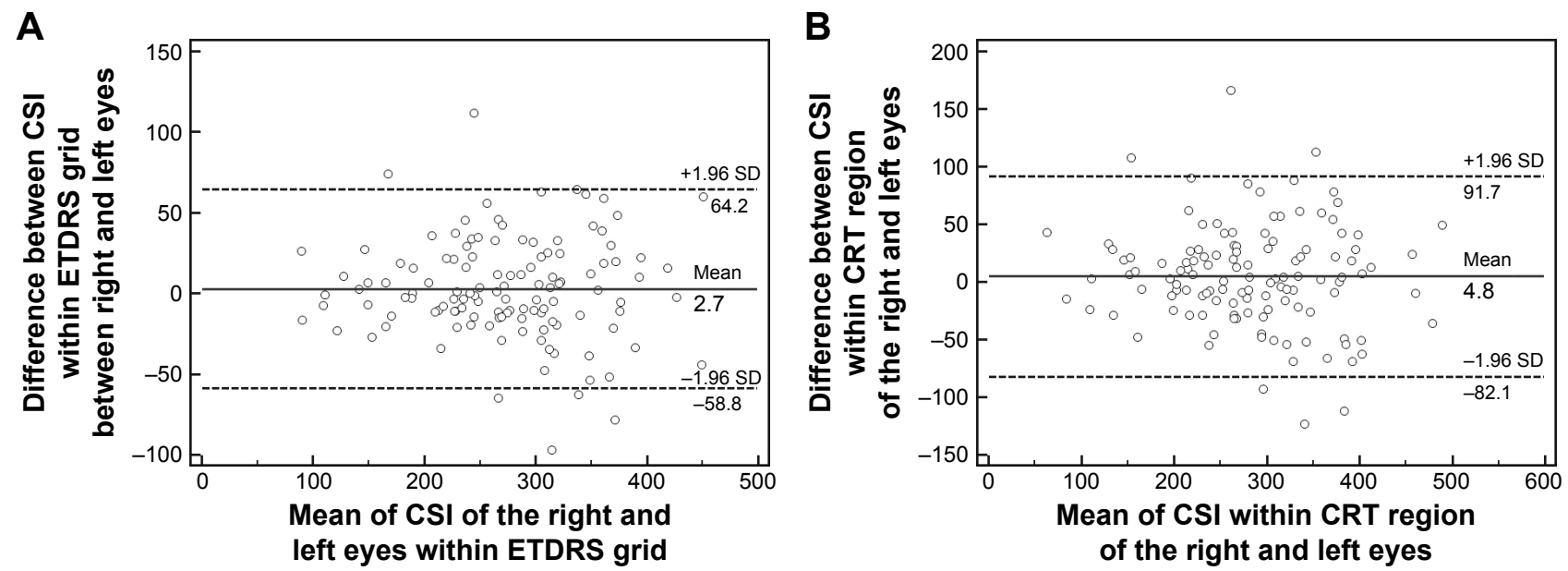

Figure 2 (A) Bland-Altman plot between CSI thickness of the right and left eyes within the $6 \mathrm{~mm}$ grid in the ETDRS grid. (B) Bland-Altman plot of CSI thickness between the right and left eyes within the CRT grid.

Abbreviations: CRT, central retinal thickness; CSI, choroidal sclera interface; ETDRS, Early Treatment Diabetic Retinopathy Study; SD, standard deviation. 
Table 3 Sample size calculations

\begin{tabular}{lllllll}
\hline Type of study & \multicolumn{5}{l}{ Total patients required } \\
& using standard deviations of: \\
\cline { 2 - 6 } & $\mathbf{5 0}$ & $\mathbf{1 0 0}$ & $\mathbf{2 0 0}$ & $\mathbf{3 0 0}$ & $\mathbf{4 0 0}$ \\
\hline $\begin{array}{l}\text { Uniocular surgery or treatment using } \\
\text { fellow eye as control (one group) }\end{array}$ & 5 & II & 36 & 78 & 136 \\
$\begin{array}{l}\text { Two groups of uniocular surgery } \\
\text { or treatment }\end{array}$ & 12 & 36 & 136 & 304 & 540 \\
\hline
\end{tabular}

Notes: $\alpha=0.05$, power $=0.9$ for all calculations. Difference to detect choroidal sclera interface thickness is set at $112 \mu \mathrm{m}$, either to the fellow eye or to other treatment/ surgery groups. Assuming no loss to follow-up. aStudent's t-test for comparing difference between two dependent mean values (matched pairs). 'Student's $t$-test for comparing difference between two independent mean values (two groups).

the overall CSI within the ETDRS grid as a logical parameter for future clinical studies. A $112 \mu \mathrm{m}$ threshold was chosen for the detection of CSI changes. Assuming a hypothetical study to detect at least a $112 \mu \mathrm{m}$ difference using the fellow eye as a control without a prior SS-OCT measurement, a sample size calculation was done for either single-arm or doublearm studies (Table 3). Hypothetical clinical studies using a threshold $<112 \mu \mathrm{m}$, such as to detect subtle changes, will increase the number of patients required and vice versa.

\section{Discussion}

With the introduction of enhanced depth imaging and sweptsource optical coherence tomography, the imaging of the choroidea has improved tremendously. Various studies have shown an association of choroidal thickening with various diseases, such as central serous chorioretinopathy, ${ }^{14,15}$ polypoidal choroidal vasculopathy, ${ }^{16}$ and uveitis. ${ }^{17,18}$ Therapeutical approaches such as intravitreal injections or surgical manipulation have also been shown to affect the choroid. ${ }^{19}$

In the present study, we demonstrated the variability of choroidal thickness in healthy subjects. We showed that choroidal thickness is influenced by many factors, such as age and axial length. However, even the same individual might have a considerable amount of choroidal thickness asymmetry between both eyes. Therefore, the results from this study are important to understand the variability of the choroid in more detail. We also use the results from this study to calculate sample size needed to design future clinical studies using choroidal thickness as one possible end point.

The standard deviation in such clinical trials might also vary considerably. It depends on which underlying disease is being investigated. In this study, we found a CSI standard deviation of $\sim 78 \mu \mathrm{m}$, assuming the same amount of standard deviation in future clinical trials, a sample size of 5-11 will be needed for a study, using fellow eye as reference. In a study with two groups, a sample size between 12 and 36 subjects will be needed (Table 3).

\section{Conclusion}

We examine the variability of retinal and choroidal thicknesses in healthy subjects in this study. The choroidal thickness might vary up to $112 \mu \mathrm{m}$ between both eyes of the same individuals. The choroidal thickness is associated with axial length and age. The sample size for future clinical studies calculated here shows us that such studies are feasible.

\section{Disclosure}

The authors report no conflicts of interest in this work.

\section{References}

1. Murthy RK, Haji S, Sambhav K, Grover S, Chalam KV. Clinical applications of spectral domain optical coherence tomography in retinal diseases. Biomed J. 2016;39(2):107-120.

2. Lavinsky F, Lavinsky D. Novel perspectives on swept-source optical coherence tomography. Int J Retina Vitreous. 2016;2:25.

3. Mrejen S, Spaide RF. Optical coherence tomography: imaging of the choroid and beyond. Surv Ophthalmol. 2013;58(5):387-429.

4. Caramoy A, Engel L, Koch KR, Kirchhof B, Cursiefen C, Heindl LM. Multiple imaging modalities for the detection of optic nerve head drusen: is echography still mandatory? Acta Ophthalmol. 2017;95(3): 320-323.

5. Zheng F, Gregori G, Schaal KB, et al. Choroidal thickness and choroidal vessel density in nonexudative age-related macular degeneration using swept-source optical coherence tomography imaging. Invest Ophthalmol Vis Sci. 2016;57(14):6256-6264.

6. Cerquaglia A, Iaccheri B, Fiore T, et al. Full-thickness choroidal thinning as a feature of Fuchs Uveitis Syndrome: quantitative evaluation of the choroid by Enhanced Depth Imaging Optical Coherence Tomography in a cohort of consecutive patients. Graefes Arch Clin Exp Ophthalmol. 2016;254(10):2025-2031.

7. Oner V, Bulut A, Buyuktarakci S, Kaim M. Influence of hyperopia and amblyopia on choroidal thickness in children. Eur J Ophthalmol. 2016;26(6):623-626

8. Abbey AM, Kuriyan AE, Modi YS, et al. Optical coherence tomography measurements of choroidal thickness in healthy eyes: correlation with age and axial length. Ophthalmic Surg Lasers Imaging Retina. 2015;46(1):18-24.

9. Ruiz-Medrano J, Flores-Moreno I, Pena-Garcia P, et al. Analysis of age-related choroidal layers thinning in healthy eyes using swept-source optical coherence tomography. Retina. 2017;37(7):1305-1313.

10. Faul F, Erdfelder E, Lang AG, Buchner A. G*Power 3: a flexible statistical power analysis program for the social, behavioral, and biomedical sciences. Behav Res Methods. 2007;39(2):175-191.

11. Faul F, Erdfelder E, Buchner A, Lang AG. Statistical power analyses using $\mathrm{G}^{*}$ Power 3.1 : tests for correlation and regression analyses. Behav Res Methods. 2009;41(4):1149-1160.

12. Gauderman WJ, Barlow WE. Sample size calculations for ophthalmologic studies. Arch Ophthalmol. 1992;110(5):690-692.

13. Caramoy A, Foerster J, Allakhiarova E, et al. Spectral-domain optical coherence tomography in subjects over 60 years of age, and its implications for designing clinical trials. Br J Ophthalmol. 2012;96(10): $1325-1330$.

14. Honda S, Miki A, Kusuhara S, Imai H, Nakamura M. Choroidal thickness of central serous chorioretinopathy secondary to corticosteroid use. Retina. 2017;37(8):1562-1567.

15. Regatieri CV, Novais EA, Branchini L, et al. Choroidal thickness in older patients with central serous chorioretinopathy. Int $J$ Retina Vitreous. 2016;2:22.

16. Lee WK, Baek J, Dansingani KK, Lee JH, Freund KB. Choroidal morphology in eyes with polypoidal choroidal vasculopathy and normal or subnormal subfoveal choroidal thickness. Retina. 2016; 36(suppl 1):S73-S82. 
17. Takahashi A, Saito W, Hashimoto Y, Ishida S. Multiple evanescent white dot syndrome associated with retinal vasculitis. Int Med Case Rep J. 2015;8:209-213.

18. Hirooka K, Saito W, Namba K, et al. Significant role of the choroidal outer layer during recovery from choroidal thickening in VogtKoyanagi-Harada disease patients treated with systemic corticosteroids. BMC Ophthalmol. 2015;15:181.
19. Yumusak E, Ornek K, Dikel NH. Comparison of choroidal thickness changes following intravitreal dexamethasone, ranibizumab, and triamcinolone in eyes with retinal vein occlusion. Eur J Ophthalmol. 2016;26(6):627-632.

\section{Publish your work in this journal}

Clinical Ophthalmology is an international, peer-reviewed journal covering all subspecialties within ophthalmology. Key topics include: Optometry; Visual science; Pharmacology and drug therapy in eye diseases; Basic Sciences; Primary and Secondary eye care; Patien Safety and Quality of Care Improvements. This journal is indexed on

Submit your manuscript here: http://www.dovepress.com/clinical-ophthalmology-journal

\section{Dovepress}

PubMed Central and CAS, and is the official journal of The Society of Clinical Ophthalmology (SCO). The manuscript management system is completely online and includes a very quick and fair peer-review system, which is all easy to use. Visit http://www.dovepress.com/ testimonials.php to read real quotes from published authors. 